Goldschmidt 2021 Abstract

https://doi.org/10.7185/gold2021.5167

\section{Al incorporation and diffusion in natural rutile: A geothermometer?}

\author{
BASTIAN JOACHIM-MROSKO ${ }^{1}$, JÜRGEN KONZETT ${ }^{1}$, \\ THOMAS LUDWIG ${ }^{2}$, EUGEN LIBOWITZKY ${ }^{3}$ AND \\ ROLAND STALDER ${ }^{1}$
}

${ }^{1}$ University of Innsbruck

${ }^{2}$ Heidelberg University

${ }^{3}$ University of Vienna

Presenting Author: bastian.joachim@uibk.ac.at

This study aims to experimentally investigate the incorporation mechanism and diffusivity of $\mathrm{Al}$ and $\mathrm{H}$ in natural rutile, thus bridging the gap between elaborate diffusion studies in defined simplified synthetic systems and complex natural systems.

High-P-T experiments were performed at pressures ranging from 1 bar to $7 \mathrm{GPa}$, and at temperatures between 1223 and 1373 $\mathrm{K}$. The samples contained natural rutiles extracted from an eclogite that were embedded in a natural metapelitic host rock at fixed $\mu\left(\mathrm{Al}_{2} \mathrm{O}_{3}\right)$ with $\Delta f \mathrm{O}_{2}$ buffered to $\mathrm{CCO}$. Based on diffusion profiles of the respective elements in rutile that were analyzed using EPMA and SIMS, Arrhenius relations were determined within the experimental temperature range of this study (equations 1 and 2).

EPMA analyses further reveal a complex distribution of oxygen defects at the scale of the diffusion profiles. FTIR analyses indicate that the incorporation of hydrogen is not related to metal impurities. Based on these results, we suggest a complex combination of mechanisms to explain the incorporation of $\mathrm{Al}$ and $\mathrm{H}$ in natural rutile and its high-pressure polymorphs. This includes (i) the incorporation of $\mathrm{Al}^{3+}$ in octahedrally coordinated Ti-sites charge balanced by the formation of oxygen vacancies and (ii) the incorporation of oxygen in interstitial positions charge balanced by hydrogen interstitials.

Al-diffusivities in natural rutile determined in this study are about 8 to 9 orders of magnitude faster than recently determined Al-diffusivities in synthetic rutile [1]. Available literature data on the Al content of natural rutiles (e.g. [2]) indicate a strong tendency of $\mathrm{Al}$ to be returned to coexisting silicates through diffusion in the wake of retrogressive re-equilibration, thus supporting the assumption that $\mathrm{Al}$ diffusivities in rutile and its $\mathrm{TiO}_{2}$-polymorphs in natural systems are comparatively fast. As a consequence, results of this study question the applicability of the Al-in-rutile geothermobarometer in natural systems.

[1] Cherniak DJ, Watson EB (2019) Al and Si diffusion in rutile. American Mineralogist 104, 1638-1649.

[2] Meinhold G (2010) Rutile and its applications in earth sciences. Earth-Science Reviews 102, 1-28.

$$
D_{A l}^{r u}\left(\frac{m^{2}}{s}\right)=3.75 \times 10^{11} \exp \left(\frac{-659 \pm 20 \mathrm{kJmol}^{-1}}{R T}\right)
$$

$$
D_{H}^{r u}\left(\frac{m^{2}}{s}\right)=3.08 \times 10^{17} \exp \left(\frac{-820 \pm 33 \mathrm{kJmol}^{-1}}{R T}\right)
$$

